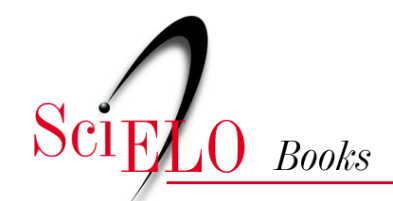

\title{
4. Manipulação e trapaças
}

\author{
Aline Guarnieri Gubitoso \\ Vinicius Cifú Lopes
}

\section{SciELO Books / SciELO Livros / SciELO Libros}

GUBITOSO, G., and LOPES, V. C. Manipulação e trapaças. In: Alocações, estabilidade e otimização: uma introdução passo a passo [online]. São Bernardo do Campo, SP: Editora UFABC, 2017, pp. 81-90. ISBN: 978-85-6857-682-3. https://doi.org/10.7476/9788568576823.0005.

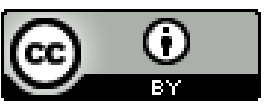

All the contents of this work, except where otherwise noted, is licensed under a Creative Commons Attribution 4.0 International license.

Todo o conteúdo deste trabalho, exceto quando houver ressalva, é publicado sob a licença Creative Commons Atribição $\underline{4.0}$.

Todo el contenido de esta obra, excepto donde se indique lo contrario, está bajo licencia de la licencia $\underline{\text { Creative }}$ Commons Reconocimento 4.0. 


\section{4 \\ Manipulação e trapaças}

Um problema de sistemas de seleção e alocação é, na realização prática, a preocupação dos candidatos em entender o processo a que serão submetidos e atuar de modo a obter o melhor resultado possível.

No modelo de alocação que consideramos, com propostas e escolhas, perceberemos a possibilidade de um candidato rejeitar uma proposta que prefira e escolher uma outra que considere pior, a fim de alcançar um resultado melhor no final do processo. Dessa forma, o agente apresentaria erroneamente suas preferências com o propósito de obter resultados diferentes, realmente preferíveis.

Assim, ao discutirmos a aplicação do algoritmo Gale-Shapley e dos programas desenvolvidos para situações do cotidiano, é necessário examinar a questão da manipulação dos dados, principalmente a partir da apresentação falsa das preferências. O ponto de partida para essa análise é o questionamento: é do interesse de todos os agentes envolvidos indicar suas verdadeiras preferências?

Verifica-se que a resposta é negativa, porque o interesse mútuo de todos os agentes em falar a verdade não ocorre em nenhum procedimento que produza soluções estáveis. (ROTH; SOTOMAYOR, 1990, p. 87) Como observamos na Seção 1.3, será necessário considerar qualquer possível procedimento, não apenas Gale-Shapley, e demonstrações formais no caso deste, não apenas nossa intuição com a movimentação das "molduras". 


\subsection{Como ocorre a trapaça}

Como um exemplo, adaptado com modificações de Roth; Sotomayor (1990, p. 81), tomamos o seguinte conjunto de preferências:

$\begin{array}{llll}\text { Victor (V): } & A>B>C>D & \text { Ana }(A): & W>X>V>Y>Z \\ \text { Wilson }(W): & D>B>A>C & \text { Beatriz }(B): & X>V>W>Y>Z \\ \text { Xavier }(X): & D>C>B>A & \text { Carolina }(C): & Z>Y>V>W>X \\ \text { Yuri }(Y): & A>D>C>B & \text { Débora }(D): & V>W>Y>Z>X \\ \text { Zé (Z): } & A>B>D>C & & \end{array}$

A partir dessas preferências, obtemos as seguintes alocações quando os homens propõem: $V-A, W-D, X-B, Y$ solteiro, $Z-C$.

Entretanto, se Ana muda sua lista de preferências, de modo a apresentar uma ordenação falsa em que diz preferir Yuri e Zé a Victor, isto é:

$$
\text { Ana (A): } W>X>Y>Z>V \text {, }
$$

obtemos outra formação de casais: $V-D, W-A, X-B, Y$ solteiro, $Z-C$.

com preferências verdadeiras

A: $\quad W>X>V>Y>Z$

B: $\quad X>V>W>Y>Z$

C: $Z>Y>V>W>X$

D: $\quad V>W>Y>Z>X$ com preferências falsas

A: $W>X>Y>Z>V$

B: $X>V>W>Y>Z$

C: $Z>Y>V>W>X$

D: $V>W>Y>Z>X$

Assim, ao apresentar erroneamente suas preferências, Ana melhora sua situação, pois se aloca ao homem que prefere verdadeiramente, enquanto que, antes, estava alocada ao seu terceiro homem mais preferível.

Além disso, Débora também é beneficiada indiretamente pela trapaça de Ana, dado que foi promovida de seu segundo homem mais preferível para o primeiro. 
Logo, para Ana, é um comportamento estratégico apresentar falsas preferências a fim de manter-se junto a um homem menos preferível dentre as propostas que recebe, para que, em alguma etapa posterior do processo, receba a proposta de um homem mais preferível que, se não fosse pela trapaça, não chegaria a lhe propor.

\section{Exercício}

1) Aplique o algoritmo Gale-Shapley aos dois conjuntos de preferências e confira o exemplo.

Porém, para que a manipulação ocorra e seja bem-sucedida, Ana teria que saber as preferências das demais pessoas a fim de realizar simulações do processo e descobrir como suas preferências falsas poderiam impor novas escolhas. As propostas inéditas a ela por seus candidatos mais preferíveis ocorrem quando as mulheres a quem eles propuseram, antes, rejeitaram-nos em favor de novas opções de parceiros e estes, por sua vez, fazem tais propostas devido às rejeições de Ana.

Assim, para trapacear e ser favorecida, ou Ana tem de ter acesso às listas de preferências das demais pessoas ou as propostas têm de ser rodadas mais de uma vez, de forma que, a partir da observação das propostas e escolhas, Ana tenha, pelo menos, um esboço das preferências.

$\rightarrow$ Definição: Estratégia é uma decisão sobre o conjunto de ações a realizar, como uma postura ou raciocínio para apresentação de informações e decisões, qualquer que seja. Cada manipulação das preferências, condicionada ou não às preferências alheias, é uma estratégia, mas ser honesto quanto a suas preferências também é uma estratégia.

$\rightarrow$ Definição: A estratégia dominante de um agente é a estratégia que melhor responde às possíveis estratégias que possam 
ser adotadas pelos demais agentes. As razões para tal estratégia, que deverá ser seguida pelo agente, acabam por esclarecer que não há nenhum incentivo a ele para que atue de forma diferente.

Assim, em uma situação-problema em geral, é importante determinar qual é a estratégia dominante de cada agente.

\section{Viabilidade da manipulação}

Para verificarmos quando a trapaça é possível, destacamos alguns resultados e informações de Roth; Sotomayor (1990, p. 87-90), referentes a um "mercado", ou conjunto de agentes, no qual as preferências são estritas e existe mais de uma alocação estável.

Ao analisar a escolha de cada agente por sua estratégia dominante, Roth constatou que não existe nenhum mecanismo de alocação estável em que indicar as preferências verdadeiras seja a estratégia dominante para todos os agentes. Essa observação ficou então conhecida como o Teorema da Impossibilidade de Roth. Depois, por consequência, concluiu-se que não existe nenhum mecanismo de alocação estável em que indicar as preferências verdadeiras seja a melhor estratégia para todos os agentes quando todos os outros agentes indicam suas verdadeiras preferências, ou seja, pelo menos um agente pode se beneficiar ao apresentar erroneamente suas preferências, assumindo que os outros contaram a verdade.

Adaptamos, aqui, o exemplo da demonstração dada por Roth e Sotomayor:

$$
\begin{array}{llll}
\text { Xavier }(X): & A>B & \text { Ana }(A): & Y>X \\
\text { Yuri }(Y): & B>A & \text { Beatriz }(B): & X>Y
\end{array}
$$

Só há dois emparelhamentos possíveis e ambos são estáveis: $\left(1^{\circ}\right) X-A, Y-B$, ótimo para os homens, e $\left(2^{\circ}\right) X-B, Y-A$, ótimo para 
as mulheres. Se Ana mudar sua lista para $Y>\mathbf{m}$, então somente o segundo pode ser obtido, qualquer que seja o mecanismo, garantindo sua melhor escolha. Analogamente, qualquer agente (Xavier, Yuri ou Beatriz) pode impôr que somente um emparelhamento seja possível e, então, obtido pelo mecanismo, contanto que os demais três mantenham suas listas originais.

\section{Exercício}

1) Verifique a estabilidade dos dois emparelhamentos e o sucesso das estratégias dos quatro agentes.

Gale e Sotomayor mostraram como, em uma dada situação, ao menos um agente pode trapacear: se há ao menos dois emparelhamentos estáveis, o mecanismo produz - um que é distinto ou do ótimo dos homens ou do ótimo das mulheres; um desses agentes, portanto, não atinge seu ótimo possível e beneficia-se ao remover de sua lista todos os indivíduos que considera piores que esse ótimo.

Entretanto, note que os agentes que apresentam preferências falsas são aqueles que recebem as propostas, enquanto que os agentes que propõem têm como melhor estratégia, ou estratégia dominante, indicar suas verdadeiras preferências, dado que o resultado é sempre o melhor possível para eles.

Por exemplo, considerando as seguintes listas de preferência para o uso de Gale-Shapley:

$\begin{array}{llll}\text { Xavier: } & A>C>B & \text { Ana: } & Y>X>Z \\ \text { Yuri: } & A>B>C & \text { Beatriz: } & X>Z>Y \\ \text { Zé: } & C>B>A & \text { Carolina: } & Y>X>Z\end{array}$

Com o desenrolar do processo, terminamos, na última rodada, com: 


$\begin{array}{llll}\text { Xavier: } & A>C>B & \text { Ana: } & Y>X>Z \\ \text { Yuri: } & A>B>C & \text { Beatriz: } & X>Z>Y \\ \text { Zé: } & C>B>A & \text { Carolina: } & Y>X>Z\end{array}$

Como vimos no Capítulo 1, percebe-se, pelo próprio movimento das molduras, que o homem sempre propõe primeiro à melhor opção possível disponível e, se modificar sua lista de preferências, será, então, pareado à primeira mulher preferível que o aceitar, da mesma forma que ocorre quando se falar a verdade.

\section{Exercício}

1) Aplique o algoritmo de Gale-Shapley e confira esse exemplo.

Se, nesta situação, tanto Xavier como Zé, os homens que não estiveram com sua primeira opção, inverterem suas listas de qualquer forma, vão continuar com Carolina e Beatriz como suas melhores opções possíveis, respectivamente, dado que a primeira opção de Xavier está bloqueada pelo par Ana e Yuri, que se preferem mutuamente, e, por conseguinte, a primeira opção de Zé está bloqueada pelo par Xavier e Carolina. Zé e Beatriz, mesmo cada um não sendo a primeira opção do outro, preferem-se mutuamente, pois seus parceiros "ideais" (Ana e Yuri, respectivamente) já formam um par de bloqueio, que não pode ser desfeito para que o resultado continue a ser estável. Logo, não há incentivos para eles falsearem sua lista de preferência para serem alocados a uma outra parceira.

Isso em razão de que, sendo os homens que propõem, a situação de cada um apenas pode "piorar" em termos de sua lista de preferência. Quando o processo termina, o homem conseguiu sua parceira mais preferível possível sem manipular o mecanismo, porque, se escolher alguém menos preferível numa rodada, não haverá como, posteriormente, escolher uma parceira mais preferível.

Logo, a manipulação de um homem em sua lista de preferência, quando são eles que propõem, não pode ser bem-sucedida, porque o 
resultado será para ele tão bom quanto o resultado original de suas preferências verdadeiras.

Por isso, Dubins e Freedman, assim como Roth, concluíram que o mecanismo que resulta na melhor alocação estável para os homens (nos termos de preferências indicadas) faz com que a estratégia dominante para cada homem seja indicar suas verdadeiras preferências. Ademais, é importante ressaltar que, quando são as mulheres que propõem, por simetria, ser verdadeira também é a estratégia dominante de todas elas. Portanto, de forma geral, para o grupo que faz as propostas, a melhor estratégia é sempre ser verdadeiro.

Observações: Até aqui, porém, nossas conclusões estão condicionadas a duas hipóteses: 1) Somente tratamos homens monogâmicos. Um agente proponente com várias "vagas" pode constituir uma “coalizão" dessas vagas e obter vantagens, como destacaremos na próxima seção. 2) Ademais, não estamos considerando possíveis "externalidades", isto é, incentivos como propinas para que um homem altere sua lista de preferências. Assumimos que os agentes proponentes, nesse raciocínio, somente agem em seu próprio benefício e somente em vista da alocação obtida.

\subsection{Coalizões}

Vimos que, para todo agente que faz as propostas, a melhor política é a honestidade, já que não há necessidade de esses agentes modificarem suas preferências para obterem resultados melhores.

Também é possível mostrar que, considerando os agentes que propõem, uma coalizão deles (isto é, um subconjunto) também não obtém incentivos o suficiente para desejar manipular suas preferências, porque não há uma alocação que todos os integrantes da coalizão prefiram, de modo que a melhor estratégia é ser verdadeiro. (ROTH; SOTOMAYOR, 1990, p. 92, devido a Dubins e Freedman)

$\rightarrow$ Definição: Coalizões são reuniões de dois agentes ou mais que agem em conjunto a fim de alterar o resultado das alocações. 
Portanto, para qualquer agente do grupo que propõe, a melhor estratégia, tanto individual como de coalizão, é ser verdadeiro.

Entretanto, como falsear suas preferências pode ser uma estratégia dominante para algumas pessoas do grupo que recebe as propostas, também pode ser estratégico para uma coalização de indivíduos deste grupo, de forma que seus indivíduos escolham a trapaça como sua estratégia dominante.

Por exemplo, as mulheres podem negociar entre si a escolha de um emparelhamento estável qualquer, até mesmo aquele que é ótimo para elas, e, então, cada mulher apresentar uma lista incompleta de preferência, consistindo apenas do homem que lhe cabe nesse emparelhamento. Dessa maneira, qualquer mecanismo de alocação estável, mesmo Gale-Shapley com propostas feitas pelos homens, produzirá, precisamente, esse emparelhamento (ROTH; SOTOMAYOR, 1990, teo. 4.15 devido a Gale e Sotomayor). Ou, em nosso primeiro exemplo, Débora solicitar a Ana que manipule sua lista de preferência, em benefício de si mesma, mas, também, ajudando à primeira.

\section{Quando a coalizão provê algo mais}

Até aqui, a noção que temos de uma coalizão é a de um mero conjunto de agentes. É preciso considerar, todavia, que uma coalizão, como um clube exclusivo, também possa oferecer a seus membros benefícios externos ao mercado em questão.

Assim, um homem (como agente proponente) pode, apresentando listas incompletas, alterar significativamente o resultado final sem se prejudicar. Se uma coalizão de outros homens se interessar nisso e subornar este homem, pode, então, construir resultados mais favoráveis a si mesma. (ROTH; SOTOMAYOR, 1990, s. 4.3.1.)

Essa situação é especialmente relevante no casamento poligâmico, porque indica que as vagas proponentes (de um mesmo homem) podem realizar uma coalizão. Veremos um exemplo disso na Seção 5.3, que demonstra uma universidade $A$ que pode melhorar de situação, mesmo quando universidades propõem. (Lá, poderá usar a lista 
$W>Y>V>X$, cf. Roth; Sotomayor, 1990, teo. 5.14.) Os candidatos, sendo monogâmicos, porém, não têm motivo para trapacear quando propõem. (op. cit., teo. 5.16, e nossa discussão)

\subsection{Evitando a trapaça}

Face a toda essa discussão, qualquer projeto prático de mecanismo para alocações estáveis deve ter, em sua concepção, a preocupação de induzir os agentes ao comportamento honesto, ou limitar o incentivo à trapaça. Podemos, a partir da observação dos exemplos e técnicas descritos, esboçar algumas regras heurísticas:

A primeira é impedir que os agentes submetam listas de preferência muito curtas ou sequer incompletas, consistindo somente de suas opções mais preferíveis. Naturalmente, com uma lista assim, o agente assume, também, o risco de não ser alocado (ou "ficar solteiro").

Outra é, em situação de poligamia ou oferta de vagas que constituem coalizões, fazer com que os agentes poligâmicos formem o grupo seletor e não o proponente.

$\mathrm{O}$ sistema pode incluir um mecanismo de desfavorecimento dos agentes quando trapaceiam e a trapaça não é bem-sucedida ou é detectável e existe um elemento fiscalizador (ou externo ou formado por um grupo de agentes). Isso torna a ação de trapacear desnecessária ou prejudicial e deixa de "valer a pena". Um exemplo disso pode ser formulado entre estudantes e universidades: caso uma universidade admita alunos com notas baixas demais para seu padrão, sua credibilidade e imagem exterior acabarão prejudicadas perante toda a comunidade. Consequentemente, ela poderá deixar de receber inscrição de novos candidatos devido à desconfiança, de forma que, num futuro próximo, tenha dificuldade para admitir estudantes.

Além disso, pode-se impor a condição de que cada agente está preocupado com sua própria alocação, de forma a não se interessar em ajudar outros agentes. Porém, para que isso assim seja, não deve haver externalidades, como incentivos financeiros de um agente ao outro, 
para que um agente não seja convencido por outro a trapacear, mesmo que sua alocação continue a mesma enquanto que aquele que o incentivou melhore de situação (em razão da qual oferece o incentivo). Esta é outra necessidade de fiscalização externa ao mercado.

Costuma-se, em geral, atribuir o papel de proponente ao grupo de agentes que deva ser melhor alocado, para obter seu ótimo. Sem dúvida, essa estratégia se particulariza às questões de manipulação, porque será oportuno identificar esse grupo como o que também seja mais difícil de fiscalizar, enquanto os agentes seletores possam ser orientados apenas com base em sua reputação.

Outro mecanismo utilizado para se evitar a trapaça é a realização do processo de alocação uma única vez para evitar que, ao estudar os resultados, os agentes mudem suas estratégias para obter melhores resultados numa tentativa posterior.

Finalmente, descobriu-se, também, que os benefícios da trapaça são limitados e minimizados quando o mercado é suficientemente grande e cada participante interage com poucos agentes do outro grupo. Esse é um exemplo de resultado primeiramente indicado por simulações computacionais e, depois, explicado teoricamente. (ROYAL SWEDISH ACADEMY of SCIENCES, 2012b, p. 14; ROTH; PERANSON, 1999 [resumo]) 